\title{
JULIA CODORNIU (1854-1906) O CUANDO LA LITERATA SE HACE EDITORA
}

\author{
SYLVIE TuRC-ZINOPOUlOS \\ Université Paris-Nanterre
}

\begin{abstract}
El artículo evoca la figura de Julia Codorniu (1854-1906), escritora hoy olvidada, pero quien, gracias a su implicación en la edición de sus obras por cuenta propia, dejó testimonios de sí misma como agente cultural en la República de las Letras españolas, bajo la Restauración, principalmente entre 1882 y 1885 . A través de las estrategias que desarrolla, se sigue el proceso de elaboración del objeto-libro desde la composición del texto a la adquisición por parte del lector-consumidor. Con el presente artículo se pretende renovar la imagen de la mujer de pluma, ya no solo creadora sino también artífice involucrada en la impresión, la publicación, la difusión y hasta en la venta de sus libros, necesaria para adquirir la anhelada emancipación y el estatus de profesional reconocida en la sociedad de su época.
\end{abstract}

PALABRAS CLAVE: Julia Codorniu, escritora, editora, siglo XIX, España.

\section{Julia Codorniu or When the Woman Writer Becomes a Woman Editor}

The article touches on the figure of Julia Codorniu (1854-1906), writer nowadays forgotten but who, thanks to her investment in self-publishing, left evidence of her involvement in the Spanish Republic of Letters, following the Restauration, mainly between 1882 and 1885 . Through the strategies she devised, we can follow the process of creation of the book-object from the text composition to its acquisition by the reader-consumer. With this contribution, we intend to renew the image of the woman-writer, not only as creator, but also as craftswoman involved in the printing, publishing, distribution and even the selling of her books, necessary for her to acquire the sought-after emancipation and the status of recognized professional in the society of her time.

KEY WORDS: Julia Codorniu, woman writer, woman editor, 19th century, Spain.

Tradicionalmente, los estudios literarios suelen disociar la producción de una obra de su difusión posterior, como si su autor(a) se despreocupara de ella; como si la creación siguiera su propia vida en manos ajenas, las de un(a) editor(a); como si la escritura estuviera totalmente desconectada del mercado del que depende; como si un libro no necesitara venderse para que su creador(a) se granjeara fama y, al tiempo, algunas ganancias como profesional de las Letras.

Turc-Zinopoulos, Sylvie (2019), "Julia Codorniu (1854-1906) o cuando la literata se hace editora", Lectora, 25: 119-133. ISSN: 1136-5781, sylvie.turc-zinopoulos@u-paris10.fr, D.O.I.: 10.1344/ Lectora2019.25.7

Recepció: 15 de desembre de 2018 - Acceptació: 15 d'abril de 2019 
Julia Codorniu y Matta (Manila, Filipinas, 28/10/1854-Madrid, 16/5/1906), bajo su nombre completo, empieza a hacerse visible en la escena literaria madrileña a partir de la publicación de su primer libro Las fraguas de Pont-Avesnes en 1882, una versificación de la novela original de Georges Ohnet, a la que suma treinta y cuatro poesías propias agrupadas bajo el título Ensayos poéticos. La escritora aparece como arquetipo de aquellas autoras españolas del siglo XIX que se hacen editoras por la mera necesidad de existir. El estudio del corpus asequible de sus obras - la mayoría de los volúmenes son ilocalizables-, compuesto de Doctrina explicada (1883), de las dos series de Dramas de familia (1884e; 1885) y de La Semana Literaria, periódico madrileño que dirige entre el 8 de marzo y el 30 de noviembre de 1884, proporciona elementos de primera mano para comprender su doble implicación como autora y editora.

En efecto, Julia Codorniu se involucra en el mundo de la edición como único medio para darse a conocer con la esperanza de emanciparse profesionalmente y también de su marido, Gregorio Corrochano Velada, del que vive separada desde 1880 , después de tres años de unión. Este trabajo se propone examinar las estrategias de que se vale Julia Codorniu para editar sus obras, distinguiendo dos fases distintas, en las que se verá a la literata-editora en el centro de una red a través de la cual se relaciona con otros profesionales del libro -impresores, ilustradores, libreros- y con el lector, ya no solo como destinatario del relato, sino como comprador potencial a quien hay que seducir. Tal paradigma ensancha nuestra concepción de la literatura: ya no se trata de considerar solo el texto producido, sino también de pensar tanto en su devenir como en las etapas previas a su conversión en objeto-libro (Fernández, 2017).

\section{Publicar con una identidad femenina}

La edición de una obra no resulta fácil para un autor novel, y menos si se trata de una autora. En los años que nos ocupan, sigue vigente un prejuicio desfavorable a las mujeres que cultivan las Letras. Impera aún el modelo del "ángel del hogar”, exaltado por la literatura de la domesticidad de una María del Pilar Sinués de Marco o de una Faustina Sáez de Melgar, quienes valoran a la hija obediente, a la esposa sumisa y a la madre abnegada - tres perfiles femeninos promocionados tanto por la sociedad conservadora como por la Iglesia católica (Blanco, 2001). La literata rompe, pues, con el canon dominante al salir de la esfera privada "natural" que se le asigna. Por añadidura, un discurso seudocientífico difunde la idea de la supuesta inferioridad intelectual de la mujer; incluso una acérrima defensora de la causa femenina como Concepción Arenal vacila, según confiesa en La mujer de su casa, al puntualizar su posición: "Debemos declarar que hoy no abrigamos aquel íntimo convencimiento de la igualdad de inteligencia de los sexos, manifestado en 
La mujer del porvenir. Nuevos hechos observados, y una reflexión más detenida, nos han inspirado dudas que sinceramente exponemos" (1883: 101).

Julia Codorniu no comparte esa desvalorización de las mujeres. Para combatir semejantes estereotipos, se hace portavoz de sus congéneres y se lanza a una contraofensiva con su "Defensa de las escritoras injustamente atacadas en el folleto de D. Antonio Cortón titulado La literata" (1884a: 1-3), pues la negación de las dotes intelectuales y culturales de las literatas desacredita sus creaciones y dificulta el propósito de publicación. En palabras del cínico Antonio Cortón, una vez compuesta su obra, le toca a la autora preocuparse por "un interés mezquino: la conquista de un editor responsable" (Cortón, 1883: 28). Contraargumenta Julia Codorniu, en el mencionado texto: “¿quién le ha dicho [a ese señor] que los libros de las literatas son despreciados en todas las librerías y ninguna los admite a la venta?" (1884a: 2). Sea o no verdad que el panfletista acentúa la caricatura, es de notar que, en los pies de imprenta de los libros de Julia Codorniu, no figura ningún editor, solo aparecen impresores. Un editor, al igual que un librero, desconfiará de un nombre femenino todavía desconocido. El libelo de Cortón, por cruel que sea, alude a una realidad.

Por eso, como muchos/as colegas, Julia Codorniu edita sus obras por cuenta propia en la década de 1880. En efecto, a pesar de vivir en Madrid con sus dos hijos menores, separada de su esposo residente en Calera (provincia de Toledo) - se divorciará de él quod thorum et habitationem por sevicia y adulterio el 19 de enero de 1900_, ${ }^{1}$ disfruta de un caudal personal elevado; probablemente este proceda

\footnotetext{
${ }^{1}$ Es el resultado de una demanda dirigida al Provisorato y a la Vicaría General de Toledo el 16 de febrero de 1897. En efecto, las "Pruebas de testigos" naturales de Calera, Oropesa y Alcañizo, relatan los malos tratos sufridos por Julia Codorniu, víctima al mismo tiempo de la presión familiar ejercida por su padre Antonio Codorniu y su suegro Gerónimo Corrochano para que se resigne a su condición de malcasada. Es el reverso de la vida pública que trasluce en los Dramas de familia, que disfrazan entre líneas una autobiografía, la de su vida matrimonial desastrosa. Y el "calvario" sigue, de 1896 a 1905, con sus hijos, Antonio y Gregorio, quienes exigen la privación de la patria potestad y no vacilan en acusar a su madre de llevar una vida disoluta con varios amantes, e incluso de haber abandonado un hijo en la Inclusa. El contexto familiar y graves achaques de salud explicarían la desaparición progresiva de Julia Codorniu de la República de las Letras con la publicación - y probablemente la última edición- de Mis versos anunciados en $\mathrm{La}$ Correspondencia de España (11/12/1894: 2). Sobre el particular, se pueden consultar los "Autos sobre divorcio a instancia de Doña Julia Codorniu y de La Matta vecina de Calera contra su esposo Don Gregorio Corrochano de igual vecindad”, Toledo, Provisorato y Vicaría General, 1897, en Arzobispado de Toledo, Archivo Diocesano; así como los "Recursos de casación por infracción de ley. Doña Julia Codorniu de la Matta en autos con Don Antonio y Don Gregorio Corrochano Codorniu sobre privación de la patria potestad y otros extremos", Audiencia de Madrid, Tribunal Supremo, nº. 606, Año de 1905, Archivo Histórico Nacional, Madrid.
} 
de bienes parafernales, ${ }^{2}$ a los que suma las 50 pesetas que cobra como primera redactora "desde la fundación de La Crónica de la Moda y de la Música [...] por cada número que ella redacta" (Servat y Macía, 1884: 2), así como diversas ganancias procedentes de sus colaboraciones en la prensa madrileña. De este modo, Julia Codorniu financiará sus publicaciones sin ayuda ajena. Goza de una independencia económica y de una libertad de acción que no serán las de sus compañeras de Letras. Se convierte, pues, en editora de sus propios volúmenes, según la definición que propone Pedro Pascual de dicho oficio: "biográficamente se considera editor a toda persona o entidad que edita, sin tener en cuenta su situación jurídica, si paga impuestos a Hacienda o no, si tiene la situación legalizada o no, etc.” (1994: 341).

En cuanto a su identidad femenina, la escritora sortea la dificultad, vinculándola al renombre de su ilustre familia. ${ }^{3}$ Por eso, cuando La Correspondencia de España se refiere al "doctor en medicina y académico D. Antonio Codorniu” lo asocia naturalmente a su hija, mencionándolo como "padre de la conocida escritora del mismo nombre" (22/10/1883: 2). Con la eliminación a sabiendas del apellido del marido, la autora sabe sacar ventaja de tal notoriedad familiar que le confiere, de modo indirecto, un prestigio susceptible de captar la atención del comprador potencial de sus volúmenes.

Pero, antes del encuentro del anhelado lector con el objeto-libro, etapa final que va a otorgar a Julia Codorniu un verdadero estatus de profesional de las Letras, esta ha de elaborar, de antemano, una estrategia que consiste en darse a conocer en el espacio público.

\footnotetext{
${ }^{2}$ En los "Autos sobre declaración de pobreza a instancia de Don Gregorio Corrochano Velada, vecino de Calera, contra Doña Julia Codorniu su esposa" y en la "Sentencia: Corrochano-Codorniu del Tribunal, Toledo, 3/2/1900" (folio 1 ) se detallan los haberes de la escritora, "consistentes en dos casas en Madrid que rentan 6.000 pesetas libres y 100.000 pesetas en acciones del Banco de España". Se trata de una casa en la calle del Noviciado, 6, y otra en la de Leganitos, 41 de Madrid (Provisorato y Vicaría general de Toledo, clases: Pobres, nº. 7, año 1898, Arzobispado de Toledo, Archivo Diocesano).

${ }^{3}$ Entre los cuales, el padre, Antonio Codorniu y Nieto Samaniego (1817-1892) y el no menos famoso abuelo, Manuel Codorniu y Ferreras (1788-1857). Del primero, recuerda La Iberia el 15 de enero de 1892 en su esquela su pasado de "Doctor en Medicina y Cirugía, Inspector jubilado de 1a. clase de Sanidad Militar y Jefe que fue del mismo Cuerpo en las islas Filipinas, ex-director del Hospital Militar de Madrid, Académico de número de la Real de Medicina, miembro de varias Sociedades científicas y literarias, condecorado con las cruces de San Fernando, Carlos III, Epidemias y otras por acciones de guerra, etc.". Del segundo, Casimiro Servat y Macía señala en $\mathrm{La}$ Semana Literaria que fue "gran médico, Director General del cuerpo de Sanidad Militar, [...] uno de los generales que más se distinguieron en su época y a quien el Duque de la Victoria (Espartero) apreció mucho y colmó de distinciones" (17: 1-2).
} 


\section{Antes de editar: hacerse un nombre}

Julia Codorniu se beneficia de un contexto cultural favorable con el aumento relativo de la alfabetización, la liberalización de la prensa (Ley Gullón, 1883), el crecimiento de las ciudades y los sistemas y vías de transporte, factores que explican un aumento de la demanda de letra impresa. ${ }^{4}$ Los periódicos desempeñan pues un papel importante: le proporcionan un sueldo más seguro y regular que la venta hipotética de un libro y la acercan a un público más amplio, por ser su precio inferior al de un tomo.

La escritora, lo mismo que otras como Faustina Sáez de Melgar (Partzsch, 2017: 8-12), se vale de los medios periodísticos para lograr fama. Así, dio sus primeros pasos en varios diarios madrileños: El Álbum del Tocador, La Moda Ilustrada, La Guirnalda, La Correspondencia de España y su suplemento quincenal $L a$ Crónica de la Moda y de la Música, Flores y Perlas ${ }^{5}$ y La Semana Literaria.

Los diarios son soportes de la primera publicación de sus obras, en la sección del folletín por entregas, sin necesidad de desembolso por parte de la autora. Es el caso de la Doctrina explicada (1883), que se publicó en La Patria, y de Los pecados capitales (1884 y 1885), en la Crónica de la Moda y de la Música, también publicada en fragmentos para estimular la curiosidad del abonado de La Semana Literaria. Luego, la posterior edición del texto en un libro la hace por cuenta propia. Entonces, la autora se aprovecha de las mismas páginas periodísticas en las que se inserta una publicidad gratuita y eficaz; la información llega directamente a los posibles consumidores a quienes pretende conquistar. La notoriedad del diario, que se convierte en mentor influyente, respalda a la autora. Con habilidad, Julia Codorniu cuida confiar el prólogo de la Doctrina explicada al Sr. Alba Salcedo, director de La Patria y dedica Los pecados capitales “Al señor Don Hilarión de Zuloaga, Administrador de La Correspondencia de España [...] en testimonio de amistad”.

\footnotetext{
4 "Los años ochenta registraron las mayores cifras, sobre todo los 60 editores de 1882, para volver a situarse entre los 39 de 1890 y los 44 de 1900, con la recesión que acusó la economía y el sector editorial en la última década del siglo" (Pascual, 1994: 37).

${ }^{5}$ María del Pilar Palomo Vázquez enumera "las cinco revistas, cuyas páginas ofrecen un mayor número de textos escritos por mujeres. [...] El Correo de la Moda, muy por delante del resto (dirigida por Ángela Grassi y luego Joaquina García Balmaseda), El Álbum Ibero Americano (dirigida por Concepción Gimeno de Flaquer), Flores y Perlas (dirigida por Sinués), La Violeta (dirigida por Faustina Sáez de Melgar) y La Madre de Familia (dirigida por Enriqueta Lozano)" (2014: s.p.).
} 


\section{La Semana Literaria: vitrina publicitaria de Julia Codorniu}

Con La Semana Literaria, la directora Julia Codorniu toma las riendas de su destino. Transforma la publicación en verdadero escaparate de sus producciones poemas, artículos, novelas y pasajes de sus Dramas de familia. Ofrece un panorama completo de sus capacidades profesionales y se esmera en construir su imagen pública, sometida a su estricto control personal.

Sigue la autora con la promoción de su obra docente en los anuncios de la revista, en la que se puede leer esta detallada referencia comercial: "Doctrina explicada, explicación reflexivo-literaria del texto cristiano, por Julia Codorniu. Este precioso librito de instrucción, indispensable a los niños, forma un tomo de 250 páginas, y se halla de venta al precio de 6 reales en la Administración de este periódico". La colocación de la noticia, en la última página, en medio de otros anuncios, como los de la Zapatería del Porvenir, la gran fábrica de bujías de La Estrella o el Agua de Carabaña, purgante-refrescante-depurativo-antibilioso por excelencia, desacraliza el objeto libro, tratado como una mercancía más de la librería-bazar polivalente descrita por Jean-François Botrel (1998: 203-205) donde se venden géneros de toda índole. El periódico necesita anunciantes heterogéneos, fuente de apreciables ingresos.

Para crear "la marca de fábrica" Julia Codorniu, se conjugan varios soportes materiales en los números de La Semana Literaria. La misma escritora se presenta "al lector amigo" con un poema, "Mi retrato" (1884f: 1) que revela la intimidad de un ser sufrido, víctima de un destino adverso que se consuela con la maternidad, mientras que artículos como "La prostitución tolerada" (1884c: 1-3) o "Defensa de las mujeres...” (1884a: 1-3) muestran una pluma al servicio de su sexo. Paralelamente, las voces masculinas se centran en resaltar la figura de la profesional, como en la extensa y detallada bio-bibliografía confiada a Casimiro Servat y Macía (1884), precedida de un fotograbado de Laporta que asocia la "marca" con "el producto" para el consumidor-lector. Por fin, la portada de los dos últimos números de La Semana Literaria se transforma en un auténtico rótulo en que el administrador, Gregorio Pueyo, da a conocer estos Dramas en una reseña digna de los anuncios de los mejores libreros. Precisamente, ¿será este Gregorio Pueyo el famoso librero de la madrileña calle de Mesonero Romanos, vinculado años después con el Modernismo y convertido en el personaje valleinclaniano de Zaratustra en Luces de Bohemia? (Buil Pueyo, 2010; Fernández Menéndez, 2015).

Es en el artículo "Escena de redacción” (1884b: 1-3) donde la escritora-editora se revela; donde teatraliza su profesionalidad. Así, se presenta como una mujer muy atareada; trabaja; recibe a solas, en horas de oficina ("de dos a cuatro"), a un mal dibujante que solicita la publicación de sus obras; goza, pues, del poder de contratar, o no, a un hombre, invirtiendo los papeles de género normalmente 
admitidos; selecciona los escritos que los abonados le envían para los siguientes números; se empeña en deconstruir el estereotipo difundido por Antonio Cortón de la incultura e incompetencia de las literatas, como cuando el crítico ironiza: "El lector grave y circunspecto [...] no sabe que el articulejo de la interesante Amarilis, que tan bonito le parece, está hecho en colaboración con el director del periódico que puso mano en la sintaxis, y con el corrector de pruebas que enmendó la ortografía" (1883: 6).

Julia Codorniu no necesita ayuda alguna: ella es la directora; ella es la correctora, como se complace en subrayar: "pongo mi trabajo, que no es pequeño, teniendo que arreglar, o mejor diré que hacer de nuevo, multitud de versos y artículos que se me dirigen y que sin arreglo y pulición no podrían ser insertados, pues hay algunos que son una verdadera fusilería a las musas y al sentido común" (1884b: 2).

Y mejor se saborea la inversión del cliché al fijarse en que la mayoría de los textos publicados en La Semana Literaria procede de plumas masculinas. Consciente de ser una agente cultural, la escritora-editora-directora reivindica, ya en el primer número de la citada revista (1884: 8), su contribución a la ilustración de la mujer en la línea del periódico del mismo nombre que saluda su aparición. ${ }^{6}$ Julia Codorniu se involucra en una red de publicaciones destinadas al bello sexo, como lo sugiere la viñeta de la portada firmada por Capuz y "sus niñas laboriosas" con sus habitus de clase - rezo, bordado, lectura, música. No obstante, no se limita a este público femenino de las clases medias.

Con El paseo de los melancólicos de Sebastián López de Arrojo (1884: 2-3) Julia Codorniu se hace mentora de plumas masculinas, lo que prueba que la oposición binaria comúnmente admitida (hombre/mujer, espacio privado/espacio público, emoción/razón) no resulta tan pertinente como se pudiera pensar (Kerber, 1988: 9-39; Valis, 2015: 83-109). En las páginas de La Semana Literaria se interconectan los espacios culturales. Así, la publicista patrocina a un desconocido, José del Solar, poeta que considera digno de admiración y muy prometedor. Pero poco dada a correr demasiados riesgos, se limita a proponer unos poemas y, al tiempo, se rodea de plumas expertas, como la de un Carlos Frontaura, para atraer al público-lector. Como editora, respeta un equilibrio entre autores de renombre y otros en ciernes para procurar la permanencia de la empresa. Desde esta perspectiva, la gestión del periódico se asemeja a la de una editorial.

\footnotetext{
${ }^{6}$ Se trata de La Ilustración de la Mujer (1884, 20: 160) de Barcelona, cuya representante en Madrid es doña Josefa Pujol de Collados.
} 


\section{Pasar del texto al objeto-libro}

El proceso para que nazca el libro supone que la escritora se preocupe por la factura del tomo que ha de resultar del manuscrito. Pero, ¿cómo se define un libro? Según la Ley de Imprenta de 26 de julio de 1883:

Art. $3 .^{\circ}$ : Se entiende por libro todo impreso que, sin ser periódico, reúna en un solo volumen 200 o más páginas. Se entiende por folleto todo impreso que, sin ser periódico, reúna en un solo volumen más de ocho páginas y menos de 200. Es hoja suelta todo impreso que, sin ser periódico, no exceda de ocho páginas. (Pascual, 1994: 47)

Así, Julia Codorniu reúne, en un solo ejemplar de 297 páginas, su trasposición en verso de Le maître de forges (1882), de Georges Ohnet, obra a la que suma sus propios Ensayos poéticos. El título traducido, Las fraguas de Pont-Avesnes. Novela de Ohnet. Romancero seguido de varias poesías de dicha señora, focaliza la atención en el best seller del momento, mucho más atractivo que los poemas de una principiante que versifica el texto original del autor francés como si fuera una nueva creación. Al responder a la demanda de un público lector, aficionado a este tipo de literatura melodramática, la autora adapta su estrategia de venta que consiste en sacar provecho del éxito, ya seguro, del novelista galo para dar a conocer sus propias creaciones.

La escritora se pondrá de acuerdo con el impresor respecto a los aspectos formales del libro. Al consultar los Apuntes bibliográficos de Juan P. Criado y Domínguez (1889), se deduce que ella se dirige a los profesionales de los periódicos madrileños donde trabajaba y que figuran en los pies de imprenta de sus obras. El taller de La Guirnalda, situado en la calle de las Pozas n ${ }^{\circ} 12$, se encarga de Las fraguas... en 1882; y Francisco G. Pérez -impresor de La Patria, en Valverde no 35, en 1884, y Ballesta 9, bajo, en 1885- de los dos tomos de los Dramas de familia (1884-1885). Posiblemente la elección implique una vinculación profesional quizás personal-, o simplemente una utilización de los tipos compuestos común al folletín del diario y al libro impreso, por lo que solo se tendría el coste del papel. Para la Doctrina explicada (1883), Julia Codorniu elige a Celestino Apaolaza, ubicado en la calle de Mayor $\mathrm{n}^{\circ} 122$.

Asimismo, la escritora-editora cuidará del formato. Al mencionar la Doctrina

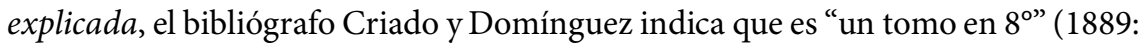
88) - tamaño también de Los dramas de familia. Julia Codorniu insiste en la relevancia de las dimensiones al referirse, en el Prólogo, a los volúmenes de los Padres Claret y Mazo, "obras muy buenas en sí, [...] pero son demasiado grandes y extensas para que se puedan tener siempre a mano" (1883: 10). Para su obra, la escritora prefiere una especie de cómodo libro de bolsillo, que acompaña al lector a lo largo 
del día, como un amigo espiritual con quien intercambiar a placer opiniones. Esta elección repercute en la estructura del tomo, compuesto de muchos capítulos que no sobrepasan las tres páginas y se centran en lo esencial del asunto abordado. Esta estructura se ajusta a una propuesta de lectura; es decir, influye en el modo de leer, posible en cualquier lugar o momento, sin necesaria continuidad o dependencia con temas ya abordados en el libro.

En los Dramas de familia que ilustran, con historietas emocionantes y recreativas, la austera teoría de la Doctrina explicada, se ofrece la misma posibilidad: el lector lee el pecado capital o el mandamiento que le apetece. Se le propone un total de diecisiete relatos cortos en dos volúmenes, con un idéntico esquema narrativo melodramático que desemboca, tras varios golpes de efecto argumentales, en el ineluctable y terrible castigo del pecador. Pero su publicación anterior, por entregas, en la prensa, dificulta a veces una lectura continua en el formato volumen, por ser inadecuado el texto a ese nuevo soporte. Así, resulta pesado cuando la autora no deja de recapacitar sobre lo ocurrido; acto inútil en un relato de apenas cincuenta páginas. Sea para la Doctrina explicada o los Dramas de familia, la elección del formato y la estructura interna del libro, segmentado en unidades narrativas cortas, se adaptan perfectamente a un lector aficionado a la variedad temática y a los textos de poca extensión reunidos en un tomo solo, de manejo fácil, que enseñan deleitando sin una exigente dedicación de tiempo.

$\mathrm{Al}$ abrir el libro, aparece de inmediato la mención de la propiedad intelectual. Miembro de la Asociación de Escritores y Artistas desde el 2 de octubre de 1883, como lo señala El Constitucional. Diario de Valencia (4/10/1883), Julia Codorniu defiende sus derechos. La mención legal la define como profesional de las Letras. Además, siendo editora por cuenta propia, se protege de la posibilidad de que los impresores o los libreros pirateen sus obras. Participa pues en ese movimiento de inscripción en el Registro de la Propiedad Intelectual que, desde la promulgación de la Ley de 1879, va en aumento según los datos aportados por Pedro Pascual (1994: 426) en los años que nos ocupan: 1882, 603 inscripciones; 1883, 713; 1884, $798 ; 1885,712$.

Además de la selección del formato, la portada, la tipografía, la organización de la página y la corrección de las pruebas, con su consabida fe de erratas final, la autora-editora inserta ilustraciones en los Dramas de familia. Estas se sitúan aparte, entre el anuncio del nuevo pecado capital o mandamiento y el principio de la narración. Tales imágenes - debidas al dibujante Urrutia y al fotograbador Laporta- contextualizan el texto que sigue a continuación. Presentan el momento cumbre del drama esclarecido por una frase extraída del relato que el lector reconocerá al encontrarla de nuevo. Responden a la vez a la exigencia de mostrar el castigo reclamado por la literatura edificante y de satisfacer la afición del público ávido de historias efectistas. Suponen la plusvalía que se encarece en el reclamo de 
venta a cargo de Gregorio Pueyo, quien insiste en la calidad de las "siete láminas en excelente cartulina" (1884, 26 y 27: 1) de Los pecados capitales.

Después de la realización del objeto-libro en colaboración con el impresor, Julia Codorniu debe considerar la distribución y la venta. A estas alturas, los paratextos, tanto autoriales como editoriales, que cierran los volúmenes revelan otras facetas de la mujer de Letras que sale al encuentro de otros profesionales del libro.

\section{La escritora y los libreros}

Es de suponer que la escritora soñará con su obra expuesta en el escaparate de una librería. Lamentablemente, entre 1868 y 1914, el librero en España no desempeña forzosamente su papel de intermediario comercial y cultural, según el retrato poco alentador que esboza de él Jean-François Botrel (1998: 196-197).

Objeto inaccesible, por la misma configuración espacial que no le permite el acceso directo a los libros, el comprador necesita solicitar al vendedor el tomo deseado de la librería, lo que implica que ya se ha enterado de su aparición y materia. De ahí, la relevancia de la publicidad hecha, como vimos en el caso de Julia Codorniu, por Enrique Cámara (1885), Casimiro Servat y Macía (1884) o Gregorio Pueyo (1884) en La Semana Literaria, pero también, en los periódicos en que ella colabora.

Sin embargo, existían buenas librerías en la capital, donde residía y trabajaba la escritora. Si se toma el ejemplo de La cuestión palpitante (1883) de Emilia Pardo Bazán, obra contemporánea de los Dramas de familia, el paratexto editorial cita como distribuidores las librerías madrileñas de Victoriano Suárez (Jacometrezo, 72); Fé (Carrera de San Jerónimo, 2) y Gutenberg (Príncipe, 14). Lista a la que se puede añadir la de Mariano Murillo, en la calle de Alcalá, 7, cuyo Boletín de la Librería (1873-1906) — uno de los mejores en el Madrid de la Restauración- señala un gran surtido de libros - nuevos y antiguos - a sus clientes. En él, se anuncia la publicación de las obras de Julia Codorniu con las debidas informaciones bibliográficas - nombre de la autora, título del libro, lugar de edición, impresor, formato, número de páginas, precio, número de referencia. ¿Quién le comunicó a Mariano Murillo tal información? ¿La misma autora, el impresor, o Gregorio Pueyo que firma un anuncio similar en La Semana Literaria?

El mes de publicación tiene su importancia. Al fijarse en el corpus seleccionado, se ve que la escritora-editora da a la luz sus libros entre noviembre y enero, meses en que se preparan las fiestas navideñas y se regalan libros. El momento parece pues idóneo para la venta; se trata de eso: de vender para ganarse la vida y de ser reconocida como profesional de las Letras. Se plantea entonces la cuestión del precio. 
Pedro Pascual insiste en el desnivel del poder adquisitivo en la sociedad canovista al afirmar: "Hay que pensar que el trabajador en ese tiempo no podía gastar dinero en adquirir libros ni en España había un hábito de lectura que impulsara a la lectura y, mucho menos, a la compra de libros" (1994: 33). En comparación, estima el kilo de pan en 0,47 céntimos en 1883. Por eso, Julia Codorniu valora lo módico de sus tomos. La Doctrina explicada "se venderá al ínfimo precio de 1 peseta 50 céntimos el ejemplar". El precio, resaltado en negrilla, se indica junto al número de páginas (248 págs.), a modo de buena relación precio/calidad, tanto más cuanto que el argumento comercial pone de realce la "sana moral" destinada a todo/a lector/a, es decir "a toda persona sensata y religiosa". Cumple la mujer de Letras las expectativas de un público deseoso de una literatura que tiene por base la religión; público que será muy importante, dadas las abundantes reediciones de obras de este tipo, como las de una María del Pilar Sinués, por citar un solo ejemplo. La literatura "virtuosa" ofrece a una principianta oportunidades ciertas de carrera y de ganancias.

Preocupada por atraer público de distinto nivel adquisitivo, la escritora-editora promueve dos ediciones de Los pecados capitales: una de lujo a 3 pesetas y otra más barata a 2 pesetas el ejemplar. La diferencia de tarifa se justifica por la calidad del papel: uno, "fuerte y satinado"; otro, "económico" (Pueyo, 1884: 1). Los suscriptores de La Semana Literaria, clientes privilegiados, se benefician de un descuento de 50 céntimos en cada tipo de edición y, al abonarse a la revista, de un ejemplar gratis de la Doctrina explicada. El libro elegante adornará la estantería de un hogar acomodado, signo de su nivel de vida y de su cultura; el más económico entretendrá a las clases modestas. La diversificación de la oferta incrementa, por supuesto, el número potencial de lectores.

Instructivo resulta el paratexto autorial y editorial de Las fraguas..., incluido en la última página, por proponer un contrato destinado a "los señores libreros de provincias que deseen obtener rebaja al por mayor, y los señores particulares que deseen ejemplares sueltos". A los primeros presenta una disminución de "un real, siempre que el pedido pase de 12 ejemplares" con "el porte [...] de cuenta del comprador". Dicho pedido va acompañado del pago adelantado, en "previa libranza o sellos". Tales condiciones comerciales corresponden a las prácticas de la época. En cuanto a la rebaja de $12,5 \%$, sobre el tomo de 2 pesetas, parece inferior al habitual 25 \% de descuento (Botrel, 1998: 218). Julia Codorniu no alienta a los libreros de provincias que responden a una demanda limitada y no quieren quedarse con existencias, ya pagadas de antemano. Fuera de ciudades dinámicas con numerosas librerías como Barcelona, Oviedo o Valencia (Botrel, 1998: 113), las obras de Julia Codorniu, que apenas empieza a ser conocida, se venderán poco en provincias.

Julia Codorniu indica también su propio domicilio madrileño, calle de Amaniel, 15, tercero derecha, en 1882 para la venta de Las fraguas..., y la calle de 
Santiago, 2, bajo derecha, para la Doctrina explicada en 1883. Se confunden el espacio privado y el espacio público por su interpenetración. El hogar se convierte en librería donde guardará un stock de sus libros. La escritora-editora gestiona los pedidos, los envíos y el cobro, lo que implica todo un trabajo de secretaría y de contabilidad que no se imagina en una mujer de Letras. El objeto-libro exige un tiempo de dedicación restado a la creación. Pero, la creación necesita este sacrificio por la comercialización del libro. Es el precio para entrar en la economía de mercado.

La última página de la Doctrina explicada hace las veces de catálogo bibliográfico destinado tanto a los lectores como a los libreros. En efecto, recuerda la voz editorial de Julia Codorniu los títulos de las obras ya publicadas. Así se descubre que inicialmente los Dramas de familia se denominaban Historietas familiares y que se ha invertido el orden de la publicación, al empezar con Los pecados capitales, previstos para la segunda serie. El cambio del título, nada anecdótico, más atractivo, desvela la rivalidad existente con María del Pilar Sinués, quien publica a la par los suyos $(1883 ; 1885)$. La bibliografía presenta también los libros "en preparación", desafortunadamente perdidos, como Amores desventurados, "novela seguida de poesías y artículos". Hoy en día, se convierte en testimonio que da fe de la existencia de tales tomos e indica la diversidad de las producciones de Julia Codorniu.

Para concluir, este trabajo nos ha invitado a modificar la imagen de la mujer de Letras, ya no solo responsable de sus textos. Al involucrarse en la edición, se ocupa del objeto-libro, desde su misma fabricación con el impresor hasta su publicación y difusión entre libreros y lectores. Se adapta a la demanda de lectura de estos, al proponer una literatura "virtuosa" que un público conservador y religioso espera de una pluma femenina, pero satisface también su gusto por los melodramas sensacionalistas que le permiten dar libre expresión a su creatividad. Opta por narraciones breves que se pueden leer sin respetar un orden determinado y obedecen más bien al antojo de cada cual.

La concepción del libro como una mercancía remite a la cuestión del dinero. ¿Se gana la vida la escritora con sus obras?, para parafrasear la pregunta formulada en 1904 por la revista El Gráfico a los/as autores/as de renombre. Emilia Pardo Bazán no menosprecia las ganancias que derivan del hecho de ser leída. Y confiesa: "Conjeturo que en el tiempo que llevo de sacar partido de ella [la literatura] habré cobrado sobre 75.000 duros. Parece mucho así, en número redondo, y alarma; repártase entre tantos años de labor activa, casi incesante, y se verá que es modesto" $(1904,1)$.

En el caso de Julia Codorniu, su fortuna personal le permite consagrarse a su pasión y editar por cuenta propia. Goza de una situación excepcional: aunque separada del marido, cría sola a sus dos hijos en Madrid. Emancipada, solo depende 
de sí misma y la gestión de sus rentas - acciones del Banco de España, entre otras- le garantiza su independencia, que pone al servicio de su pluma. Parece obvio que no obtiene ganancias de la publicación de sus obras, pero esta la hace visible en la República de las Letras y evidencia cierta porosidad entre los espacios - privado/público, femenino/masculino- considerados demasiado desconectados unos de otros. En ese sentido, la escritora encarna el punto de encuentro entre la producción del texto, la fabricación del libro, su difusión y su venta. Nos ofrece una figura profesional mucho más diversificada y global que la reducida a la escritura.

Si Julia Cordoniu no ganó dinero en su tiempo, al menos logró cierto reconocimiento y, gracias a su implicación en la edición, no se han perdido todas sus obras que, hoy en día, la salvan del olvido. Sin que lo supiera, fue la suya, en cierto modo, una inversión a largo plazo.

\section{REFERENCIAS BIBLIOGRÁFICAS}

Arenal, Concepción (1883), La mujer de su casa, Madrid, Gras y Compañía Editores.

Blanco, Alda (2001), Escritoras virtuosas. Narradoras de la domesticidad en la España isabelina, Granada, Colección Feminæ, Universidad de Granada.

Botrel, Jean-François (1998), La diffusion du livre en Espagne (1868-1914), Madrid, Bibliothèque de la Casa de Velázquez.

Buil Pueyo, Miguel Ángel (2010), Gregorio Pueyo (1860-1913). Librero y editor, Madrid, CSIC, Instituto de Estudios Madrileños, Ediciones Doce calles.

Cámara, Enrique (1885), "Juicio del conocido periodista señor Cámara sobre la obra titulada Los pecados capitales", Los pecados capitales. Primera serie de dramas de familia, Madrid, Imprenta de Francisco G. Pérez: 417-420.

Codorniu, Julia (1882), Las fraguas de Pont-Avesnes. Novela de Ohnet. Romancero seguido de varias poesías de dicha señora, Madrid, Imprenta y litografía de La Guirnalda.

-(1883), Doctrina explicada, Madrid, Apaolaza.

-(1884a), "Defensa de las escritoras injustamente atacadas en el folleto de D.

Antonio Cortón titulado La literata", La Semana Literaria, 4: 1-3.

—(1884b), "Escena de redacción”, La Semana Literaria, 22: 1-3.

—(1884c), "La prostitución tolerada", La Semana Literaria, 1: 1-3.

-(1884d), "Las peinadoras", La Semana Literaria, 11: 1-3.

-(1884e), Los pecados capitales. Primera serie de dramas de familia, Madrid, Imprenta de Francisco G. Pérez. 
-(1884f), "Mi retrato", La Semana Literaria, 3: 1.

-(1885), Los mandamientos del Señor, dramas de familia, Madrid, Imprenta de Francisco G. Pérez.

Cortón, Antonio (1883), La literata. Agua fuerte, Madrid, Tipografía de Manuel G. Hernández, Librería del Guio.

Criado y Domínguez, Juan P. (1889), Literatas españolas del siglo XIX. Apuntes bibliográficos, Madrid, Imprenta de Antonio Pérez Dubrull.

Fernández, Pura (ed.) (2017), “'Por ser mujer y autora...' Identidades autoriales de escritoras y artistas en la cultura contemporánea", Ínsula. Revista de letras y ciencias humanas, 841-842. < https://www.insula.es/sites/default/files/artíc ulos_muestra/purafernandez_-_copiar.pdf >

Fernández Menéndez, Raquel (2015), “Gregorio Pueyo (Panticosa, Huesca, 1860 Madrid, 1913) [Semblanza]", portal Editores y Editoriales Iberoamericanos (siglos XIX-XXI), EDI-RED, Alicante, Biblioteca Virtual Miguel de Cervantes. $<$ http://www.cervantesvirtual.com/obra/gregorio-pueyo-panticosa-huesca-18 60---madrid-1913-semblanza/

Kerber, Linda K. (1988), “Separate Spheres, Female Worlds, Woman’s Place: The Rhetoric of Women's History”, Journal of American History, 75 (1): 9-39.

Murillo, Mariano (1876-1906), Boletín de la Librería, Madrid, Librería de Murillo.

Palomo Vázquez, María del Pilar (2014), "Las revistas femeninas españolas del siglo XIX. Reivindicación, literatura y moda”, Arbor: Ciencia, pensamiento $y$ cultura, CSIC, 767: a130. <http://dx.doi.org/10.3989/arbor.2014. 767n3001>

Pardo Bazán, Emilia (1883), La cuestión palpitante, Madrid, Imprenta Central a cargo de V. Sáiz.

—(1904), “¿Cuánto ha ganado usted con sus libros?”, El Gráfico, 38: 1.

Partzsch, Henriette (2017), "Mujeres de letras y de negocios. Faustina Sáez de Melgar y el mercado de las revistas de modas isabelinas (1834-1895)", Ínsula. Revista de letras y ciencias humanas, 841-842: 8-12.

Pascual, Pedro (1994), Escritores y editores en la Restauración canovista (18751923): Tomo I, Madrid, Ediciones de la Torre.

Pueyo, Gregorio (1884), "Nuestro grabado", La Semana Literaria, 26 y 27: 1.

Servat y Macía, Casimiro (1884), "Julia Codorniu”, La Semana Literaria, 17: 1-3.

Sinués, María del Pilar (1883), Dramas de familia. Primera serie. Madrid, Impr. Viuda e hijos de J. García.

-(1885), Dramas de familia. Segunda serie. Madrid, Agustín Júbera Editor.

Valis, Noël (2015), "Patronazgo masculino y visibilidad de las escritoras románticas españolas y norteamericanas", No hay nación para este sexo. La $\mathrm{Re}(d)$ pública transatlántica de las Letras: Escritoras españolas $y$ 
latinoamericanas (1824-1936), Pura Fernández (ed.), Madrid y Frankfurt, Iberoamericana-Vervuert: 83-109.

\section{(c) (1) () $\Theta$}

